\title{
Measurement of Diaphragmatic Electrical Activity by Surface Electromyography in Intubated Subjects and Its Relationship With Inspiratory Effort
}

\author{
Giacomo Bellani MD PhD, Alfio Bronco MD, Stefano Arrigoni Marocco MD, Matteo Pozzi MD, \\ Vittoria Sala MD, Nilde Eronia MD, Giulia Villa MD, Giuseppe Foti MD, \\ Giovanni Tagliabue MD, Marcus Eger PhD, and Antonio Pesenti MD
}

\begin{abstract}
BACKGROUND: Quantification of patient effort during spontaneous breathing is important to tailor ventilatory assistance. Because a correlation between inspiratory muscle pressure $\left(\mathbf{P}_{\text {mus }}\right)$ and electrical activity of the diaphragm $\left(\mathbf{E A}_{\mathrm{di}}\right)$ has been described, we aimed to assess the reliability of surface electromyography (EMG) of the respiratory muscles for monitoring diaphragm electrical activity and subject effort during assisted ventilation. METHODS: At a general ICU of a single university-affiliated hospital, we enrolled subjects who were intubated and on pressure support ventilation (PSV) and were on mechanical ventilation for $>48 \mathrm{~h}$. The subjects were studied at 3 levels of pressure support. Airway flow and pressure; esophageal pressure; $\mathbf{E A}_{\mathrm{di}}$; and surface EMG of the diaphragm (surface $\mathbf{E} \mathbf{A}_{\mathrm{di}}$ ), intercostal, and sternocleidomastoid muscles were recorded. Respiratory cycles were sampled for off-line analysis. The $P_{\text {mus }} / E A_{d i}$ index (PEI) was calculated by relying on $\mathbf{E A}_{\mathrm{di}}$ and surface $\mathbf{E A _ { \mathrm { di } }}$ (surface PEI) from an airway pressure drop during end-expiratory occlusions performed every minute. RESULTS: surface $\mathbf{E A _ { d i }}$ well correlated with $\mathbf{E A}_{\mathrm{di}}$ and $P_{\text {mus }}$, in particular, after averaging breaths into deciles $(R=0.92$ and $R=0.84)$. When surface PEI was used with surface $E A_{d i}$, it provided a reliable estimation of $P_{\text {mus }}(R=0.94$ in comparison with measured $\mathbf{P}_{\text {mus }}$ ). CONCLUSIONS: During assisted mechanical ventilation, $\mathbf{E A}_{\mathrm{di}}$ can be reliably monitored by both $\mathbf{E A} \mathbf{d i}_{\mathrm{di}}$ and surface EMG. The measurement of $\mathbf{P}_{\text {mus }}$ based on the calibration of $\mathbf{E A}_{\mathrm{di}}$ was also feasible by the use of surface EMG. Key words: mechanical ventilation; pressuresupport ventilation; electrical activity of the diaphragm; surface electromyography; esophageal pressure. [Respir Care 2018;63(11):1341-1349. @ 2018 Daedalus Enterprises]
\end{abstract}

\section{Introduction}

During patient triggered ventilation, the patient and the ventilator share the work of breathing. Whereas excessive

\footnotetext{
Drs Bellani, Bronco, Arrigoni-Marocco, Pozzi, Sala, Eronia, Villa, and Foti are affiliated with the School of Medicine and Surgery, University of Milan-Bicocca, Monza, Italy, and Department of Emergency and Intensive Care, San Gerardo Hospital, Monza, Italy. Mr Tagliabue is affiliated with the Department of Critical Care Medicine, University of Calgary, Calgary, Alberta, Canada. Dr Eger is affiliated with Draeger Medical, Luebeck, Germany. Dr Pesenti is affiliated with Istituto di Anestesia e Rianimazione, Università degli Studi di Milano, Ospedale Maggiore, Istituto di Ricovero e Cura a Carattere Scientifico, Milan, Italy.
}

This work was supported by departmental funds and by an unrestricted grant from Draeger Medical (Luebeck, Germany). ventilatory assistance has been associated with patientventilator asynchrony and muscle atrophy, ${ }^{1,2}$ low support can lead to fatigue and might contribute to lung edema and inflammation because of the negative intrathoracic pressure generated by the respiratory muscles. ${ }^{3,4}$ Hence, an approach aimed to titrate ventilator support to maintain an adequate level of diaphragm activity, the so called muscle

\footnotetext{
The study was performed at the General ICU, Department of Emergency and Intensive Care, San Gerardo Hospital, Monza, and School of Medicine and Surgery, University of Milan-Bicocca, Monza, Italy.

Dr Bellani discloses relationships with Draeger Medical Italy, Draeger Medical Germany, and Pfizer. The remaining authors have disclosed no conflicts of interest.
} 
protective ventilation, has been advocated, 5,6 Such a finetuning strategy would require direct, reliable, and continuous monitoring of the pressure generated by the respiratory muscles (muscle pressure $\left[\mathrm{P}_{\mathrm{mus}}\right]$ ). Although the standard method to measure $\mathrm{P}_{\text {mus }}$ is based on esophageal pressure $\left(\mathrm{P}_{\mathrm{es}}\right){ }^{7,8}$ several alternatives have recently become

\section{See the Related Editorial on Page 1457}

available. The continuous measurement of electrical activity of the diaphragm $\left(\mathrm{EA}_{\mathrm{di}}\right)$, by using a dedicated nasogastric tube, which records electromyography (EMG) from the crural diaphragm, provides an excellent tool to monitor respiratory drive and to detect patient-ventilator asynchrony. ${ }^{9}$

Moreover, when relying on the linear relationship between $\mathrm{EA}_{\mathrm{di}}$ and $\mathrm{P}_{\text {mus }}$, we demonstrated that their coefficient of proportionality, called the $\mathrm{P}_{\text {mus }} / \mathrm{EA}_{\mathrm{di}}$ index (PEI), also described as neuromuscular coupling, is stable (within subject) during tidal ventilation, easily computable during a short expiratory occlusion maneuver, and allows the conversion of $\mathrm{EA}_{\mathrm{di}}$ (in $\mu \mathrm{V}$ ) to $\mathrm{P}_{\text {mus }}$ (in $\mathrm{cm} \mathrm{H}_{2} \mathrm{O}$ ). ${ }^{10,11}$ However, because respiratory effort is variably distributed among the different respiratory muscles (other than the diaphragm) according to inspiratory load and muscle fatigue, ${ }^{12}$ surface EMG has been proposed as a promising technique to extend such analysis to the extradiaphragmatic muscles, ${ }^{13}$ while further reducing the invasivity of $\mathrm{EA}_{\mathrm{di}}$ recordings.

Previous studies on respiratory muscle surface EMG in healthy volunteers or subjects who were intubated and on assisted ventilation found a correlation between extradiaphragmatic muscles electrical activity and respiratory load, ${ }^{13-16}$ subjective dyspnea, ${ }^{17}$ and patient-ventilator asynchrony ${ }^{17,18}$ At the same time, surface EMG poses additional and different challenges, such as the correct electrode positioning, the loss of signal power through the tissues interposed between the muscle and the electrodes, and the potential interference between electrical signals that arises from different muscles but that are detected by the same electrodes. In addition, surface EMG samples diaphragm activity from a different window: its costal portion.

Differences between these 2 diaphragmatic portions have been a long-standing subject of seminal physiologic re-

Supplementary material related to this paper is available at http:// www.rcjournal.com.

Correspondence: Giacomo Bellani MD PhD, Department of Medicine and Surgery, University of Milan-Bicocca, Via Cadore 48, 20900 Monza, Italy. E-mail: Giacomo.bellani1@unimib.it.

DOI: $10.4187 /$ respcare. 06176

\section{QUICK LOOK}

\section{Current knowledge}

Estimating patient effort during patient triggered mechanical ventilation allows fine tuning of ventilatory support to the patient's needs and prompt recognition of over and under assistance. Although muscular pressure calculation by using esophageal pressure is the accepted standard of effort estimation, this technique poses invasiveness and reliability problems. Electrical activity of the diaphragm $\left(\mathrm{EA}_{\mathrm{di}}\right)$ measurement has been validated as a reliable alternative technique, but it requires the positioning of a dedicated nasogastric tube.

\section{What this paper contributes to our knowledge}

The $\mathrm{EA}_{\mathrm{di}}$ can be reliably and noninvasively estimated by means of surface electromyography during assisted mechanical ventilation in subjects who are intubated. $\mathrm{EA}_{\mathrm{di}}$ measured with this method can be used to predict patient effort just like the accepted standard $\mathrm{EA}_{\mathrm{di}}$. Incorporation of accessory respiratory muscles did not increase the accuracy of subject effort prediction when compared with the accepted standard method based on the esophageal pressure measurement.

search, the results of these studies were consistent with considering these 2 portions as separated muscles with different embryologic origins, ${ }^{19}$ segmental innervation, ${ }^{20,21}$ fiber composition, ${ }^{22}$ and activation pattern in response to different physiologic conditions. ${ }^{23,24}$ This phenomenon has never been studied in humans on mechanical ventilation, and its potential clinical relevance is unknown. Therefore, this study was designed to assess the bedside performance of costal diaphragm surface EMG in monitoring both $\mathrm{EA}_{\mathrm{di}}$ and $\mathrm{P}_{\text {mus }}$ during assisted ventilation. Moreover, we evaluated whether the adjunct of extradiaphragmatic inspiratory muscle monitoring provides any additional value in the estimation of subject effort.

\section{Methods}

The study was conducted in a general 8-bed ICU of a university hospital (San Gerardo Hospital, Monza, Italy). Subjects' informed consent was obtained according to the recommendations of our institutional ethical committee (San Gerardo Hospital Ethical Committee), which approved the study protocol.

\section{Study Population}

Subjects who were intubated or tracheostomized and receiving pressure support ventilation (PSV) were eligible 


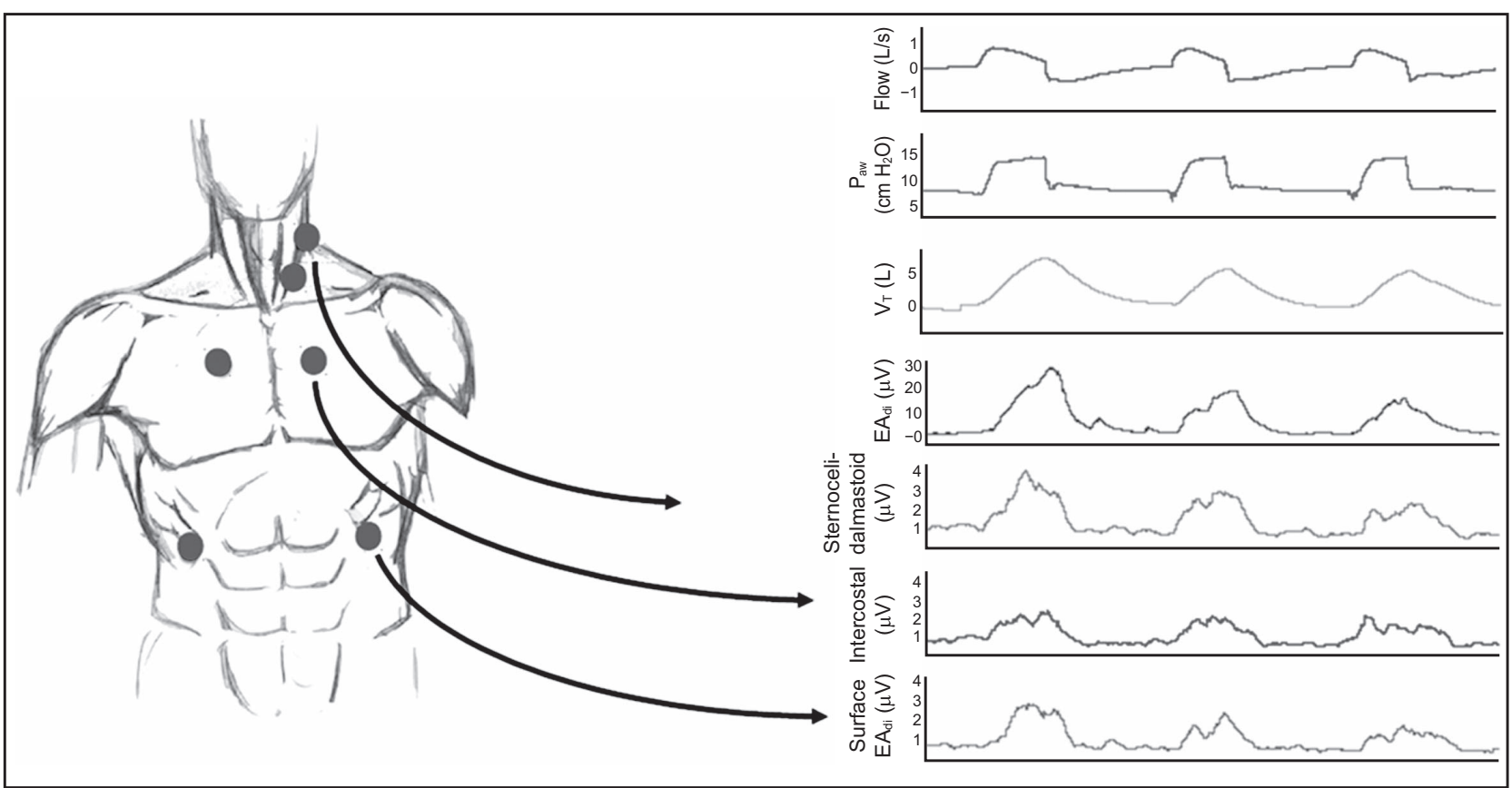

Fig. 1. Electrode positioning on the chest wall and general setup of the channel recordings. Paw = airway pressure; VT = tidal volume; EAdi $=$ electrical activity of the diaphragm.

for the study under the following criteria (1) age $\geq 18$ y; (2) on mechanical ventilation for $>48 \mathrm{~h}$, with an $\mathrm{F}_{\mathrm{IO}_{2}}<$ 0.6 and a PEEP $<.5 \mathrm{~cm} \mathrm{H}_{2} \mathrm{O}$; (3) did not receive inotropic or vasopressor support in the past $24 \mathrm{~h}$; and (4) had a Richmond Agitation-Sedation Scale score from -2 to 1 . Patients with contraindications to the positioning of a nasogastric tube were excluded.

\section{Measurements}

A nasogastric tube with electrodes for $\mathrm{EA}_{\mathrm{di}}$ detection (EDI catheter Maquet, Solna, Sweden) was positioned according to the manufacturer's recommendation. In addition, a balloon (Adult Esophageal Balloon Catheter 479005, Cooper Surgical, Trumbull, Connnecticut) for $\mathrm{P}_{\mathrm{es}}$ was positioned in all the subjects after enrollment.

The surface EMG signals were collected through 4 pairs of surface electrodes (Kendall 530 Foam Elecrodes, Covidien, Dublin, Ireland) positioned according the following scheme (Fig. 1):

1. Lower costal margin, bilaterally on the midclavicular line, for costal diaphragm (surface $\mathrm{EA}_{\mathrm{di}}$ ).

2. Second intercostal space, bilaterally on the parasternal line, for parasternal external intercostal muscles.

3. On the middle third of the sternocleidomastoid muscle, identified by palpation, on the right or left side, usually opposite to the medications for a central venous line.
The surface EMG electrodes were connected to the physiologic amplifier device Dipha 16 (Inbiolab, Groningen, NL), which amplified (gain 20), prefiltered between 0 and $200 \mathrm{~Hz}$, sampled at $500 \mathrm{~Hz}$, and then wirelessly transmitted the surface EMG signals to a dedicated acquisition system, which also collected outputs from the ventilator (airway pressure and flow) and pressure transducer (airway and $\mathrm{P}_{\mathrm{es}}$ ). Additional information (see http://www. rcjournal.com) provides more technical details about signal processing. Briefly, the raw surface EMG signal was filtered and cleaned of electrocardiogram artifacts by using a gating procedure. The envelope of the root mean square of the signal over a $250 \mathrm{~ms}$ period was taken as surface $\mathrm{EA}_{\mathrm{di}}$. Data were continuously recorded during the study and were stored on a hard drive for off-line analysis by using a dedicated device and software (Dipha Software, Dräger Medical, Luebeck, Germany).

\section{Study Protocol}

At the beginning of the study, the balloon position and inflation were checked according to the standard calibration procedure. ${ }^{25}$ The subjects underwent a protocol in which, after baseline condition (baseline step), they were studied during an increase and a reduction of pressure support (PS) by $4 \mathrm{~cm} \mathrm{H}_{2} \mathrm{O}$ (high PS and low PS steps). Every step lasted $20 \mathrm{~min}$. During each step, once per minute, during an end-expiratory occlusion, a single 
A

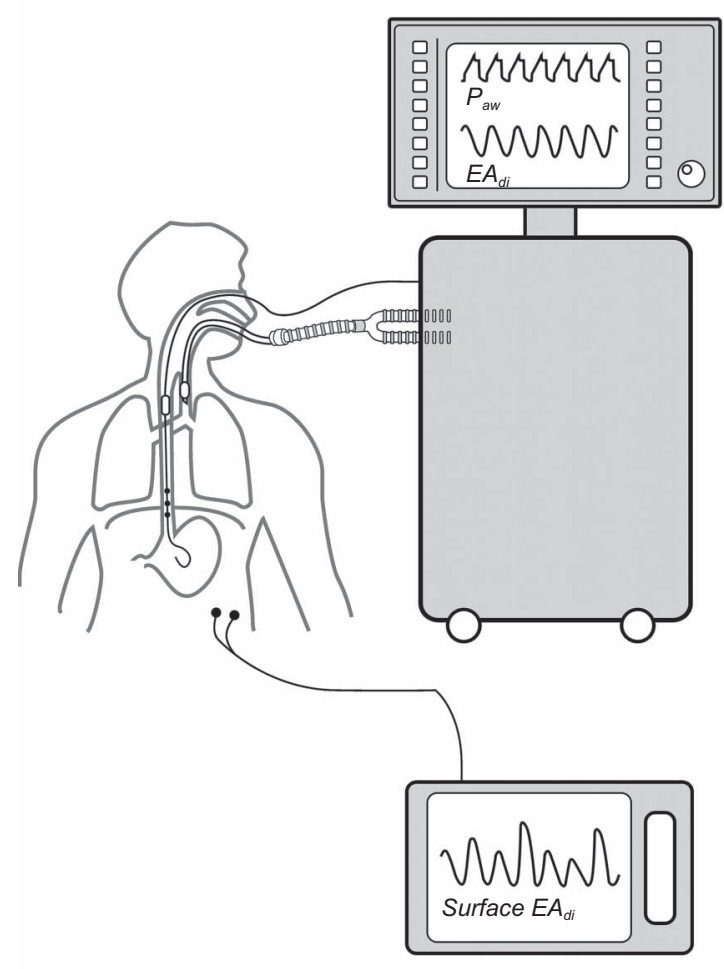

$P_{\text {mus }}$ measurement

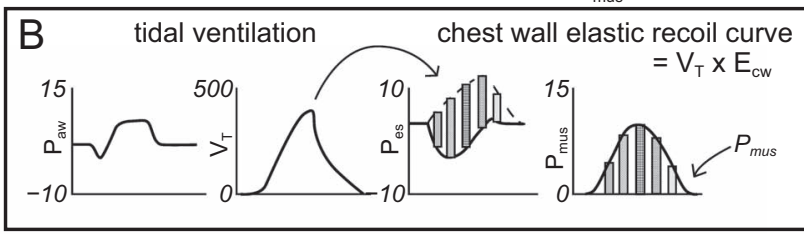

1

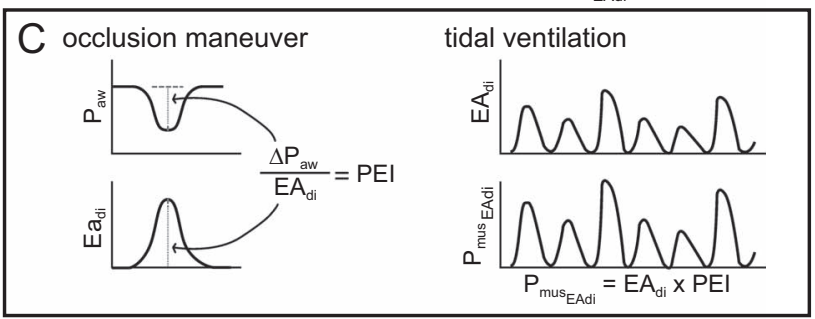

Surface $P_{\text {mus }}$ estimation

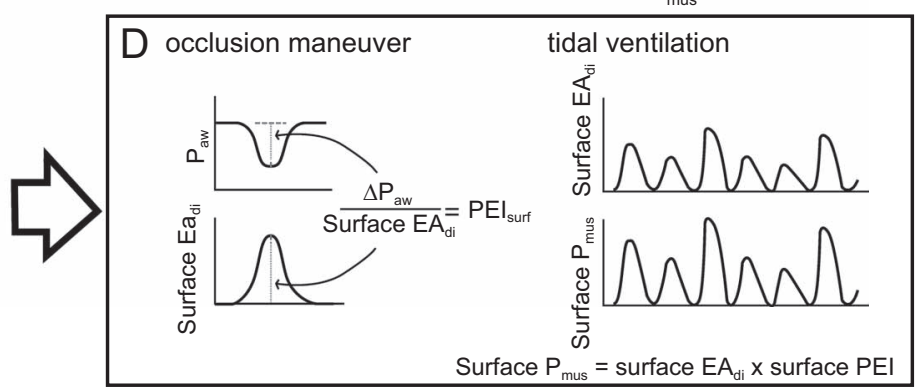

Fig. 2. Methodological issues of the 3 different modalities of muscular pressure (Pmus) calculation applied in the study. Pes-based method (B) Esophageal pressure (Pes) is measured during tidal ventilation by an esophageal balloon, and Pmus is calculated as the instant-by-instant difference between Pes and the chest-wall elastic recoil curve (equal to the instant-by-instant product of the tidal volume and chest-wall elastance, derived during the phase of controlled mechanical ventilation). EA $\mathrm{di}_{\mathrm{i}}$-based Method (C) Electromyography (EMG) of the diaphragm is continuously recorded through a dedicated nasogastric balloon, sampling crural diaphragm electrical activity $\left(E A_{d i}\right)$. Then, during a brief occlusion maneuver, the ratio between airway pressure (Paw) drops (which, in absence of flow, is equal to Pmus) and the corresponding $E A_{d i}$ signal (which is the electrical activity that the diaphragm requires to generate Pmus) is calculated. This index, the Pmus/EA $A_{d i}$ Index (PEI), indicates how much $\mathrm{cm}_{2} \mathrm{O}$ of pressure the diaphragm can produce for every $\mathrm{V}$ of electrical activity and is stable within any patient at different levels of inspiratory effort, which thus allows reliably conversion of the $\mathrm{V}$ of electrical activity into $\mathrm{cm} \mathrm{H}_{2} \mathrm{O}$ of Pmus. Finally, during tidal ventilation, $E A_{d i}$ is instant by instant converted in Pmus calculated as the product of $E A_{d i}$ and the corresponding PEI. Surface EMG-based method (D) Electrical Activity of the diaphragm is continuously recorded trough a couple of surface electrodes positioned at the lower costal margin, bilaterally on the midclavicular line, sampling costal diaphragm electrical activity (surface $E A_{d i}$ ). With the same procedure of $E A_{d i}$, Pmus/surface $E A_{d i}$ is calculated and during tidal ventilation it is used for the instant-by-instant conversion of surface $E_{d i}$ in Pmus.

inspiratory effort was recorded. Afterward, the subjects were briefly sedated and switched to controlled mechanical ventilation, with a tidal volume of $6-8 \mathrm{~mL} / \mathrm{kg}$ to measure partitioned compliance of the respiratory system with end-expiratory and end-inspiratory occlusions. $\mathrm{F}_{\mathrm{IO}_{2}}$ was left unchanged throughout the study protocol.

\section{Data Analysis}

Traces were analyzed off-line by using LabChart (ADInstruments, Sydney, Australia). For each step, 40 re- spiratory cycles were manually selected and the mean, maximum, minimum, and maximum-minimum values were calculated during both inspiration and expiration (automatically defined according to airway flow direction) for the 3 surface $E M G$ channels, $\mathrm{EA}_{\mathrm{di}}$, and $\mathrm{P}_{\text {mus. }}$. The $\mathrm{P}_{\text {mus }}$ waveform was calculated as the difference between $\mathrm{P}_{\mathrm{es}}$ and the chest-wall elastic recoil curve (equal to the instantby-instant product of the tidal volume and chest-wall elastance) derived during the phase of controlled mechanical ventilation (Fig. 2). Additional information provides more detail about off-line data processing. For an example of obtained waveforms, see http://www.rcjournal.com. 
Table 1. Demographic and Clinical Characteristics of Enrolled Subjects

\begin{tabular}{|c|c|}
\hline Characteristic & Result \\
\hline Age, mean \pm SD y & $56 \pm 12$ \\
\hline SAPS II, mean \pm SD & $39 \pm 8$ \\
\hline SOFA score, mean $\pm \mathrm{SD}$ & $8 \pm 4$ \\
\hline Men, $n(\%)$ & $12(80)$ \\
\hline \multicolumn{2}{|l|}{ ICU admission diagnosis, $n(\%)$} \\
\hline Pneumonia & $6(40)$ \\
\hline ARDS & $4(26)$ \\
\hline Sepsis & $3(20)$ \\
\hline Trauma & $1(7)$ \\
\hline Cardiac arrest & $1(7)$ \\
\hline ICU survival, $n(\%)$ & $13(86)$ \\
\hline $\mathrm{P}_{\mathrm{aO}_{2}} / \mathrm{F}_{\mathrm{IO}_{2}}$, mean $\pm \mathrm{SD} \mathrm{mm} \mathrm{Hg}$ & $235 \pm 60$ \\
\hline Clinical PEEP, mean $\pm \mathrm{SD} \mathrm{cm} \mathrm{H}_{2} \mathrm{O}$ & $10 \pm 2$ \\
\hline Clinical pressure support, mean $\pm \mathrm{SD} \mathrm{cm} \mathrm{H}_{2} \mathrm{O}$ & $7 \pm 2$ \\
\hline Intubation, mean $\pm \mathrm{SD} d$ & $12 \pm 19$ \\
\hline $\mathrm{C}_{\mathrm{RS}}$, mean $\pm \mathrm{mL} / \mathrm{cm} \mathrm{H}_{2} \mathrm{O}$ & $51 \pm 28$ \\
\hline BMI, mean $\pm \mathrm{SD} \mathrm{kg} / \mathrm{m}^{2}$ & $25 \pm 4$ \\
\hline \multicolumn{2}{|l|}{$\begin{array}{l}\text { SAPS II = Simplified Acute Physiology Score II } \\
\text { SOFA = Sequential Organ Failure Assessment } \\
\text { BMI = body mass index } \\
\text { C }_{\text {RS }}=\text { compliance of the respiratory system }\end{array}$} \\
\hline
\end{tabular}

\section{Data Aggregation}

With the aim of reducing the noise present at the single breath level, we aggregated data from respiratory cycles characterized by a similar inspiratory effort. For this purpose, $\mathrm{P}_{\text {mus }}$ that corresponded to every respiratory cycle was calculated, and the values were grouped into 10 incremental deciles. Then, in every subject, respiratory cycles that belonged to each decile were aggregated and the corresponding values of EMG signals were averaged. In this way, we obtained 10 clusters of breath per subject characterized by similar and progressively increasing values of inspiratory effort: the lowest for the cluster of breaths with a $\mathrm{P}_{\text {mus }}$ that corresponded to the first $\mathrm{P}_{\mathrm{mus}}$ decile, the highest for those that belonged to the cluster that corresponds to the 10th $\mathrm{P}_{\text {mus }}$ decile.

\section{Calculation of $P_{\text {mus }}$ From Surface EMG}

Finally, we evaluated the possibility of relating the $\mathrm{P}_{\text {mus }}$ to the $\mathrm{EA}_{\mathrm{di}}$, as already demonstrated, by means of the PEI, which indicates the amount of pressure developed by the respiratory muscles for each $\mu \mathrm{V}$ of $\mathrm{EA}_{\mathrm{di}}$. This value was also computed for surface $\mathrm{EA}_{\mathrm{di}}$ with calculation of the corresponding PEI (surface PEI $=\mathrm{P}_{\text {mus }} /$ surface $\mathrm{EA}_{\mathrm{di}}$ ) and $\mathrm{P}_{\text {mus }}$ (surface $\mathrm{P}_{\text {mus }}=$ surface $\mathrm{EA}_{\mathrm{di}} \times$ surface $\mathrm{PEI} / 1.25$ ) (Fig. 2). The coefficient 1.25 accounts for the known systemic overestimation of PEI calculated in the absence of
Table 2. Correlation Coefficient at the Single-Subject Level Between $\mathrm{EA}_{\mathrm{di}}$ and Surface $\mathrm{EA}_{\mathrm{di}}$

\begin{tabular}{lcc}
\hline \hline \multirow{2}{*}{ Subject No. } & \multicolumn{2}{c}{ R Coefficient for EA $_{\mathrm{di}} /$ surface $\mathrm{EA}_{\mathrm{di}}$ Correlation } \\
\cline { 2 - 3 } & Single Breath & Aggregated Breaths \\
\hline 1 & 0.507 & 0.851 \\
2 & 0.770 & 0.950 \\
3 & 0.874 & 0.943 \\
4 & 0.890 & 0.977 \\
5 & 0.907 & 0.990 \\
6 & 0.809 & 0.975 \\
7 & 0.654 & 0.837 \\
8 & 0.759 & 0.961 \\
9 & 0.387 & 0.922 \\
10 & 0.832 & 0.974 \\
11 & 0.839 & 0.982 \\
12 & 0.466 & 0.926 \\
13 & 0.516 & 0.813 \\
14 & 0.921 & 0.993 \\
& & \\
EA $_{\mathrm{di}}=$ electrical activity of the diaphragm & \\
surface $\mathrm{EA}_{\mathrm{di}}=$ electrical activity of the diaphragm by using surface electromyography \\
\hline
\end{tabular}

flow (during an occlusion maneuver of $2-3 \mathrm{~s}$, or in any case long enough to capture only a single inspiratory effort) above that obtained during tidal ventilation. ${ }^{10}$ Moreover, to assess the contribution of accessory muscles in generating $\mathrm{P}_{\text {mus }}$, we repeated the same above-mentioned calculation by using the sum of the inspiratory muscles (diaphragm, intercostals, and sternocleidomastoid) electrical activities (surface $\mathrm{P}_{\text {mus,sum }}$ ).

\section{Statistical Analysis}

Statistical analysis was performed by SPSS v. 21 (SPSS, Chicago, Illinois). To assess the effect of each variable on the surface EMG signal, a 2-way analysis of variance for repeated measures was performed. A correlation between variables was assessed by means of linear regression. $P<.05$ was considered statistically significant. If not otherwise specified, data are shown as mean \pm SD.

\section{Results}

Fourteen subjects were enrolled in the study. Before the study, the subjects were on mechanical ventilation for $12 \pm 19 \mathrm{~d}$, with a PEEP of $10 \pm 2 \mathrm{~cm} \mathrm{H}_{2} \mathrm{O}$, a $\mathrm{F}_{\mathrm{IO}_{2}}$ of $0.42 \pm 0.19$, and $\mathrm{a}_{\mathrm{aO}_{2}} / \mathrm{F}_{\mathrm{IO}_{2}}$ of $235 \pm 60 \mathrm{~mm} \mathrm{Hg}$. Characteristics of the population are reported in Table 1. Because all findings regarding muscular activity were not different whether we considered the mean value, the maximum value, or the swing during the inspiration (maximum-minimum), we presented only mean inspiratory values. More detailed characteristics on the enrolled subjects 

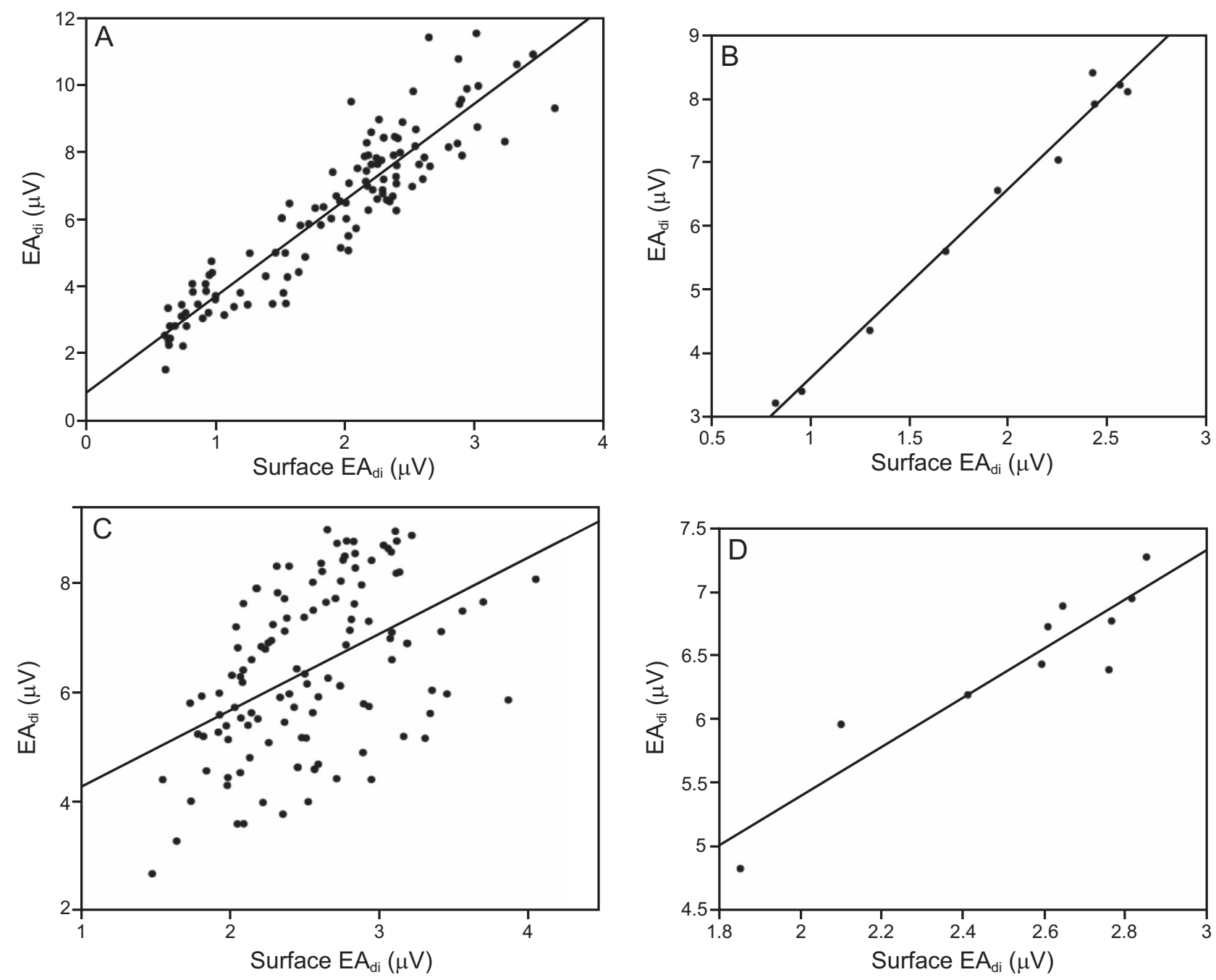

Fig. 3. Correlation between crural diaphragm electrical activity (EAdi) and sampling costal diaphragm electrical activity (surface $E A_{\text {di }}$ ) in 2 representative subjects who are the ones in which the correlation between the two variables shows the higher and the lower $\mathrm{R}$ coefficient. The correlation between EAdi and surface EAdi is shown for values that are not aggregated (120 breaths in each subject (A), along 3 study steps and after aggregation into 10 points according to deciles of muscular pressure (Pmus) (B) in the subject with the higher R coefficient ( $\mathrm{R}=0.92, P<.001$ for values not aggregated, and $\mathrm{R}=0.99, P<.001$ for aggregated values). The same correlation is shown for non-aggregated $(\mathrm{C})$ and aggregated $(\mathrm{D})$ values in the subject with the lower $\mathrm{R}$ coefficient $(\mathrm{R}=0.39, P<.001$ for values not aggregated and $\mathrm{R}=0.92, P<.001$ for aggregated values).

is provided in Supplementary File 3 (see http://www. rcjournal.com).

\section{Relationship Between EA $\mathbf{A}_{\mathrm{di}}$ and surface $\mathbf{E A _ { d i }}$}

As a first step, we assessed the correlation, on a subjectby-subject basis, between $\mathrm{EA}_{\mathrm{di}}$ and surface $\mathrm{EA}_{\mathrm{di}}$. We showed in all the subjects, a significant correlation (albeit with a large variability in the slopes), when considering both single breaths (mean $\mathrm{R}=0.72 \pm 0.36$ ) and aggregated data. The aggregation of data led to very high correlation coefficients (mean $\mathrm{R}=0.93 \pm 0.12$ ) between $\mathrm{EA}_{\mathrm{di}}$ and surface $\mathrm{EA}_{\mathrm{di}}$. Single-subject correlation between
$\mathrm{EA}_{\mathrm{di}}$ and surface $\mathrm{EA}_{\mathrm{di}}$ for aggregated and non aggregated data are shown in Table 2. The correlation in 2 representative subjects is shown in Figure 3.

\section{Calculation of $\mathbf{P}_{\text {mus }}$}

We compared $\mathrm{P}_{\text {mus }}$ measured by $\mathrm{P}_{\mathrm{es}}$ with the $\mathrm{P}_{\text {mus }}$ calculated by means of the product of $\mathrm{EA}_{\mathrm{di}}$ (expressed as $\mathrm{EA}_{\mathrm{di}}$ or surface $\mathrm{EA}_{\mathrm{di}}$ ) by using the corresponding PEI ( $\mathrm{PEI}_{\mathrm{EAdi} / 1.25}$ or surface $\mathrm{PEI}_{1.25}$ ) to obtain the relative value of $\mathrm{P}_{\text {mus }}\left(\mathrm{P}_{\text {mus EAdi }}\right.$ and surface $\left.\mathrm{P}_{\text {mus }}\right)$. A pictorial view of this process is illustrated in Figure 2. Both these measures proved to be tightly correlated with $\mathrm{P}_{\text {mus }}$ measured from 

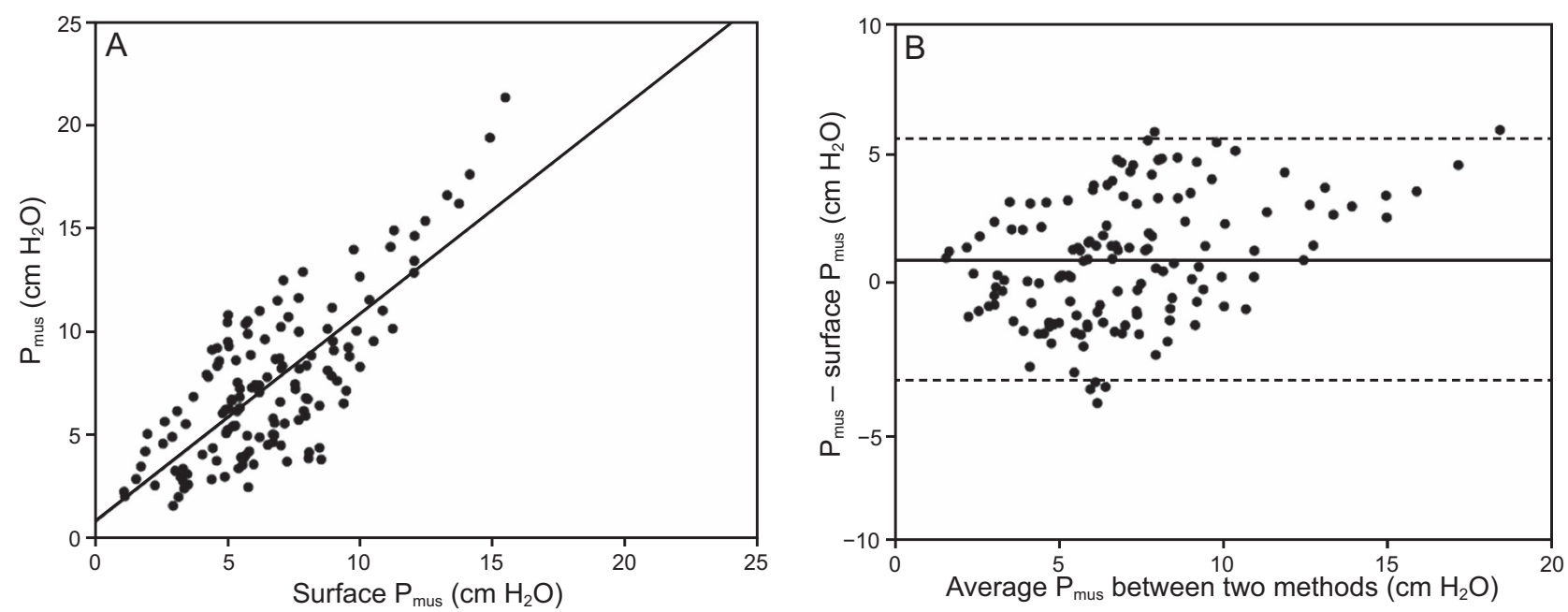

Fig. 4. Linear correlation (A) and the Bland-Altman plot for muscular pressure (Pmus) (B) calculated as the product of sampling costal diaphragm electrical activity (surface $E_{\mathrm{di}_{\mathrm{i}}}$ ) by PElsurf/1.25 (Surface Pmus) in comparison with Pmus measured by esophageal pressure. Each point represents the averaged value of a group of tidal volumes aggregated according to deciles of corresponding Pmus, on a single-subject basis. In this way, each subject is represented by 10 points. $R=0.64$. Dotted lines show the limits of agreement.

$\mathrm{P}_{\mathrm{es}}\left(\mathrm{R}=0.72, P<.001\right.$, slope of 0.81 for $\mathrm{EA}_{\mathrm{di}}$; and $\mathrm{R}=0.64, P<.001$, and slope of 1.01 for surface $\left.\mathrm{EA}_{\mathrm{di}}\right)$. The mean error for the $2 \mathrm{P}_{\text {mus }}$ measures by surface EMG in respect to $\mathrm{P}_{\mathrm{es}}$ were $1.5 \mathrm{~cm} \mathrm{H}_{2} \mathrm{O}(95 \%$ Confidence Interval from -3.3 to $6.3 \mathrm{~cm} \mathrm{H}_{2} \mathrm{O}$ ) for $\mathrm{EA}_{\mathrm{di}}$ and $0.86 \mathrm{~cm} \mathrm{H}_{2} \mathrm{O}$ (95\% Confidence Interval from -3.8 to $5.5 \mathrm{~cm} \mathrm{H}_{2} \mathrm{O}$ ) for surface $\mathrm{EA}_{\mathrm{di}}$ (Fig. 4). When taken together, these findings indicated that it was possible to compute the value of $\mathrm{P}_{\text {mus }}$ from the surface $\mathrm{EA}_{\mathrm{di}}$ signal after a PEI value was obtained during an end-expiratory hold. When taking into account the electrical activity that arises from the accessory muscles (to calculate surface $\mathrm{P}_{\text {mus, sum }}$ ) this method did not significantly improve the estimation of $\mathrm{P}_{\text {mus }}$ compared with its direct measurement based on $\mathrm{P}_{\mathrm{es}}(\mathrm{R}=0.63$, slope 0.93), with 95\% CI for the difference between the 2 methods (based on Pes and on EAdi, surface, sum) of $\pm 5.05 \mathrm{~cm} \mathrm{H}_{2} \mathrm{O}$ (from -4.31 to $5.7 \mathrm{~cm} \mathrm{H}_{2} \mathrm{O}$ ). Additional information provides a graphic illustration of the precision of the 3 methods in predicting $\mathrm{P}_{\text {mus }}$ (see Supplementary File 4 at http://www.rcjournal.com).

\section{Discussion}

The main findings of this paper can be summarized as follows: in subjects undergoing assisted mechanical ventilation, $\mathrm{EA}_{\mathrm{di}}$ can be reliably monitored by surface EMG, which provides data comparable with the transesophageal technique. Again, the measurement of $\mathrm{P}_{\text {mus }}$ based on the calibration of $\mathrm{EA}_{\mathrm{di}}$ was also feasible by using surface EMG, although incorporation of the electrical activity from accessory muscles did not improve the accuracy of $\mathrm{P}_{\text {mus }}$ estimation.
Detection of inspiratory effort in the ICU setting is important to individualize the ventilatory assistance of patients undergoing assisted mechanical ventilation. ${ }^{26}$ The breathing effort of these patients in the ICU can be estimated by measuring the electrical activity of the respiratory muscles, which, until now, has mainly been derived by relying on the measurement of $\mathrm{P}_{\mathrm{es}}$ or $\mathrm{EA}_{\mathrm{di}}$. The measurement procedures for both $\mathrm{P}_{\mathrm{es}}$ and $\mathrm{EA}_{\mathrm{di}}$ require the introduction of an esophageal probe, which has some potential drawbacks, including invasiveness, cost and technical challenges, and the inability to place a probe in some patients due to clinical reasons. As illustrated, compared with these techniques, surface EMG only requires the placement of surface electrodes.

In a previous paper, ${ }^{10}$ we showed a tight correlation between $\mathrm{EA}_{\mathrm{di}}$ and $\mathrm{P}_{\mathrm{mus}}$, which suggested that detection of the $\mathrm{EA}_{\mathrm{di}}$ can be sufficient to estimate the total inspiratory effort. The current results also showed that surface EMG could be effectively used to reliably detect the $\mathrm{EA}_{\mathrm{di}}$ and the pressure generated with high accuracy. We aggregated data on an individual basis according to deciles of $\mathrm{P}_{\text {mus }}$. With this procedure we aimed to reduce noise by creating 10 clusters of breaths with a similar inspiratory effort (ie, with a $\mathrm{P}_{\text {mus }}$ that falls into a specific percentile). This procedure increased the performance of the correlation between the electromyographic signal and the power of $\mathrm{P}_{\text {mus }}$ prediction by surface EMG. This is consistent with the evidence that, due to noise, a real-time (breath by breath) quantification of patient effort would be less reliable than an average value throughout a predefined period.

The Bland-Altman plot revealed that the discrepancy between surface EMG-derived $\mathrm{P}_{\text {mus }}$ and the standard value 
derived from $\mathrm{P}_{\mathrm{es}}$ would be, in $95 \%$ of occurrences, within -3.8 and $5.5 \mathrm{~cm} \mathrm{H}_{2} \mathrm{O}$. We believe that such a measurement error would be entirely acceptable for clinical practice, in which the goal is to ascertain the magnitude of the pressure generated by the patient and, hence, applied on the respiratory system. Even if the surface EMG technique carries a few $\mathrm{cm} \mathrm{H}_{2} \mathrm{O}$ error, this is unlikely to significantly affect the global picture.

It is known that a prolonged increased work of breathing causes a large activation of the accessory muscles, whereas the diaphragm responds to an acute increase of the respiratory load. ${ }^{27}$ Other studies found that surface EMG of upper-airway dilator (alae nasi), neck, and ribcage inspiratory muscles similarly respond to the level of ventilatory support provided. ${ }^{17}$ When we took into account the electrical activity that arose from accessory muscles in the generation of the total $\mathrm{P}_{\text {mus }}$, we found that this approach did not significantly improve the accuracy of the technique (when using $\mathrm{P}_{\text {mus }}$ as reference) compared with the use of the surface $\mathrm{EA}_{\mathrm{di}}$ value only. It is possible, however, that the levels of support we used or the duration of the periods were not sufficient to induce a more-effective recruitment of these muscles, whose role should be ascertained in other populations (eg, difficult-to-wean subjects or subjects with obstructive disease).

Our results showed that, in the subjects on mechanical ventilation with a wide range of inspiratory effort, the signals coming from crural $\left(\mathrm{EA}_{\mathrm{di}}\right)$ and costal (surface $\left.\mathrm{EA}_{\mathrm{di}}\right)$ correlated well. It is worth noting that these findings do not necessarily exclude the fact that the activation pattern of these 2 diaphragm portions could be different, as previously hypothesized. ${ }^{23,24}$ The study was not specifically addressed to this topic, and the subjects have been studied in a wide, but still physiologic, range of inspiratory effort and so were not challenged enough to develop muscle fatigue, which could have caused a different activation of the 2 diaphragm portions. That could have avoided recognizing a little difference of uncertain clinical importance. This topic should be the subject of further physiologic studies.

To the best of our knowledge, this is one of the first attempts of using surface EMG to detect the activity of inspiratory muscles in subjects undergoing assisted mechanical ventilation. Even though our results were encouraging, more studies are needed to improve the quality of surface EMG signals and to understand its real usefulness in the management of patients on ventilation.

The study had some limitations that must be taken into account. We enrolled a relatively small sample size, which, however, was comparable with that of other similar physiologic studies and was sufficient to establish the correlation of the novel technique with references such as $\mathrm{P}_{\text {mus }}$ and $\mathrm{EA}_{\mathrm{di}}$. Our cohort of subjects had relatively mild lung injury, and all were in stable condition so that they could tolerate a wide range of PS without developing respiratory distress. Moreover, we excluded patients with obstructive disease from the study, in which monitoring of the respiratory load is of paramount importance during assisted ventilation, since this monitoring can help to avoid an excessive effort to trigger the ventilator due to the presence of intrinsic PEEP.

Moreover, although obesity was not an exclusion criterion, the mean body mass index of the enrolled subjects was $25 \mathrm{~kg} / \mathrm{m}^{2}$, so these results might not be extrapolated to patients who are obese. Also, some patients could not be enrolled because the positioning of the electrodes was unattainable, such as in the presence of abdominal drainage, recent laparotomy, or substantial diaphoresis.

\section{Conclusions}

This study showed that electrical activity of the costal diaphragm can be reliably and noninvasively monitored by using surface EMG during assisted ventilation. The signal derived from the surface is tightly related to esophagealbased measurement of crural electrical activity. Both methods can be used to reliably calculate $\mathrm{P}_{\text {mus }}$.

\section{REFERENCES}

1. Thille AW, Rodriguez P, Cabello B, Lellouche F, Brochard L. Patient-ventilator asynchrony during assisted mechanical ventilation. Intensive Care Med 2006;32(10):1515-1522.

2. Goligher EC, Fan E, Herridge MS, Murray A, Vorona S, Brace D, et al. Evolution of diaphragm thickness during mechanical ventilation: impact of inspiratory effort. Am J Respir Crit Care Med 2015; 192(9): 1080-1088.

3. Bruells CS, Smuder AJ, Reiss LK, Hudson MB, Nelson WB, Wiggs MP, et al. Negative pressure ventilation and positive pressure ventilation promote comparable levels of ventilator-induced diaphragmatic dysfunction in rats. Anesthesiology 2013;119(3):652-662.

4. Toumpanakis D, Kastis GA, Zacharatos P, Sigala I, Michailidou T, Kouvela M, et al. Inspiratory resistive breathing induces acute lung injury. Am J Respir Crit Care Med 2010;182(9):1129-1136.

5. Goligher EC, Dres M, Fan E, Rubenfeld GD, Scales DC, Herridge MS, et al. Mechanical Ventilation-induced Diaphragm Atrophy Strongly Impacts Clinical Outcomes. Am J Respir Crit Care Med 2018;197(2):204-213.

6. Goligher EC, Ferguson ND, Brochard LJ. Clinical challenges in mechanical ventilation. Lancet 2016;387(10030):1856-1866.

7. Akoumianaki E, Maggiore SM, Valenza F, Bellani G, Jubran A, Loring SH, et al: PLUG Working Group (Acute Respiratory Failure Section of the European Society of Intensive Care Medicine). The application of esophageal pressure measurement in patients with respiratory failure. Am J Respir Crit Care Med 2014;189(5):520-531.

8. Mauri T, Yoshida T, Bellani G, Goligher EC, Carteaux G, Rittayamai N, et al; PLeUral pressure working Group (PLUG-Acute Respiratory Failure section of the European Society of Intensive Care Medicine). Esophageal and transpulmonary pressure in the clinical setting: meaning, usefulness and perspectives. Intensive Care Med 2016;42(9):1360-1373.

9. Colombo D, Cammarota G, Alemani M, Carenzo L, Barra FL, Vaschetto R, et al. Efficacy of ventilator waveforms observation in 


\section{Surface EMG to Determine Inspiratory EFFort}

detecting patient-ventilator asynchrony. Crit Care Med 2011;39(11): 2452-2457.

10. Bellani G, Mauri T, Coppadoro A, Grasselli G, Patroniti N, Spadaro $\mathrm{S}$, et al. Estimation of patient's inspiratory effort from the electrical activity of the diaphragm. Crit Care Med 2013;41(6):1483-1491.

11. Di Mussi R, Spadaro S, Mirabella L, Volta CA, Serio G, Staffieri F, et al. Impact of prolonged assisted ventilation on diaphragmatic efficiency: NAVA versus PSV. Crit Care 2016;20:1.

12. Butler JE. Drive to the human respiratory muscles. Respir Physiol Neurobiol 2007;159(2):115-126.

13. Parthasarathy S, Jubran A, Laghi F, Tobin MJ. Sternomastoid, rib cage, and expiratory muscle activity during weaning failure. J Appl Physiol 2007;103(1):140-147.

14. Chiti L, Biondi G, Morelot-Panzini C, Raux M, Similowski T, Hug F. Scalene muscle activity during progressive inspiratory loading under pressure support ventilation in normal humans. Respir Physiol Neurobiol 2008;164(3):441-448.

15. Hug F, Raux M, Morelot-Panzini C, Similowski T. Surface EMG to assess and quantify upper airway dilators activity during noninvasive ventilation. Respir Physiol Neurobiol 2011;178(2):341345.

16. Mezzanotte WS, Tangel DJ, White DP. Mechanisms of control of alae nasi muscle activity. J Appl Physiol 1992;72(3):925-933.

17. Schmidt M, Kindler F, Gottfried SB, Raux M, Hug F, Similowski T, Demoule A. Dyspnea and surface inspiratory electromyograms in mechanically ventilated patients. Intensive Care Med 2013;39(8):13681376.
18. Brochard L, Harf A, Lorino H, Lemaire F. Inspiratory pressure support prevents diaphragmatic fatigue during weaning from mechanical ventilation. Am Rev Respir Dis 1989;139(2):513-521.

19. De Troyer A, Sampson M, Sigrist S, Macklem PT. The diaphragm: two muscles. Science 1981;213(4504):237-238

20. Sant'Ambrogio G, Frazier DT, Wilson MF, Agostoni E. Motor innervation \& pattern of activity of cat diaphragm. J Appl Physiol 1963;18:43-46.

21. van Lunteren E, Haxhiu MA, Deal EC Jr, Perkins D, Cherniack NS. Effects of $\mathrm{CO} 2$ and bronchoconstriction on costal and crural diaphragm electromyograms. J Appl Physiol 1984;57(5):1347-1353.

22. Riley DA, Berger AJ. A regional histochemical and electromyographic analysis of the cat respiratory diaphragm. Exp Neurol 1979; 66(3):636-649.

23. Easton PA, Fitting JW, Arnoux R, Guerraty A, Grassino AE. Costal and crural diaphragm function during $\mathrm{CO} 2$ rebreathing in awake dogs. J Appl Physiol 1993;74(3):1406-1418.

24. Abe T, Kieser TM, Tomita T, Easton PA. Respiratory muscle function during emesis in awake canines. J Appl Physiol 1994;76(6): 2552-2560.

25. Baydur A, Behrakis PK, Zin WA, Jaeger M, Milic-Emili J. A simple method for assessing the validity of the esophageal balloon technique. Am Rev Respir Dis 1982;126(5):788-791.

26. Bellani G, Pesenti A. Assessing effort and work of breathing. Curr Opin Crit Care 2014;20(3):352-358.

27. Aliverti A, Cala SJ, Duranti R, Ferrigno G, Kenyon CM, Pedotti A, et al. Human respiratory muscle actions and control during exercise. J Appl Physiol 1997;83(4):1256-1269.

This article is approved for Continuing Respiratory Care Education credit. For information and to obtain your CRCE

(free to AARC members) visit

www.rcjournal.com

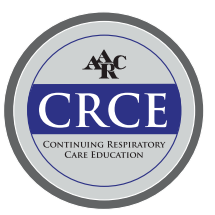

